\title{
1 Assessing Salt-Surfactant Synergistic effects on Interfacial 2 Tension from Molecular Dynamics Simulations
}

Gerard Alonso a , Pablo Gamallo a , Andrés Mejía ${ }^{\text {b }}$, Ramón Sayós a, ${ }^{*}$

${ }^{a}$ Departament de Ciència de Materials i Química Física \& Institut de Química Teòrica i Computacional (IQTCUB), Universitat de Barcelona, C. Martí i Franquès 1, 08028 Barcelona, Spain.

${ }^{b}$ Departamento de Ingeniería Química, Universidad de Concepción, POB 160-C, Correo 3, Concepción, Chile.

Abstract: In the recent years, many efforts have been carried out trying to comprehend how surfactants and salts interact among each other at the oil/brine interface to reduce the interfacial tension (IFT). To that end, the interfacial properties of several combinations of surfactants, salts and oils have been measured experimentally confirming the existence of a synergistic effect. Unfortunately, many of the proposed mechanisms for that effect arise from experimental observations, so this work, based on molecular dynamics simulations, intends to reproduce and explain this kind of phenomenon from a molecular point of view. The correct understanding of these phenomena can have application in many fields, especially in Enhanced Oil Recovery, where reducing IFT can potentially increase oil production. In this article we evaluate the effect of adding three different salts (i.e., $\mathrm{NaCl}, \mathrm{CaCl}_{2}$ and $\mathrm{MgCl}_{2}$ ) on the IFT of a water/oil system with different non-ionic surfactants. We have evaluated the effect that the ions of salt produce to surfactants, as well as the perturbation that surfactants produce on the ions. From our results, we can assess that salts (especially $\mathrm{NaCl}$ ) and surfactants are able to interact with each other, being both active species in reducing the IFT of the system.

Keywords: Molecular Dynamics simulations, Interfacial tension, Oil/water interface, Surfactant, Salt, Synergistic effect

\section{Corresponding Author}

*E-mail adress: r.sayos@ub.edu (Ramón Sayós) 


\section{Introduction}

36 The use of surfactants in Enhanced Oil Recovery (EOR) is a common practice to reduce 37 the interfacial tension (IFT) between crude oil and formation water [1-3]. The IFT reduction enhances the mobility of the crude oil within the reservoir, weakening the capillary forces, and ultimately improving oil production. The application of these compounds is usually expensive, so many studies have been focused on replacing them with other cheaper compounds. A good example is the low-salinity waterflooding, which permitted to enhance oil recovery by only controlling the salinity of the injection water in certain reservoirs $[4,5]$. However, the best performance is usually obtained with a combination of surfactants and other additives (e.g, co-surfactants) to the oil/water/surfactant mixture [6-8]. Both compounds can act cooperatively to reduce the IFT to ultralow values and can improve the stability of oil/water microemulsions [9]. Also, similar synergistic interactions were observed experimentally when using salts as additives [10-23].

Species with highly localized charge, such as ions of salts, are capable of interacting with polar molecules and polar functional groups, changing their microscopical ordering and affecting their physicochemical properties. For example, water molecules orient their dipoles towards ions in solution forming highly order solvation shells due to strong electrostatic interactions. This fact affects the water density, viscosity, surface tension, melting point, boiling point and vapor pressure [24-26]. Similarly, the ions of salts can modify the surfactant solubility in water, its Critical Micelle Concentration (CMC) [2729] or the IFT of liquid/liquid and vapor/liquid systems. In particular, the equilibrium IFT (i.e., usually called static IFT) of several water/surfactant + salt mixtures was studied by different authors, showing reductions of the IFT based on the so-called salt-surfactant synergistic effect. Some examples are the works of Staszak et al. [22], who studied a water/zwitterionic surfactant/NaCl system, Koelsch et al. [18], who analyzed different water/cationic surfactant/potassium halide salt systems or Fainerman et al. [14], who reported results for different water/anionic surfactant $/ \mathrm{NaCl}+\mathrm{CaCl}_{2}+\mathrm{MgCl}_{2}$ systems, among others $[11-13,15,16]$. Finally, these synergistic effects were mainly seen at surfactant concentrations below the $\mathrm{CMC}[18,22,23]$. Notice that the static IFT value is achieved after waiting for all species to diffuse to their equilibrium positions. During this 
process, which can take several minutes or hours, the IFT is not constant. The variation

67 of the IFT with time is called dynamic IFT and it converges smoothly to the static IFT. However, this property is also affected by the salt-surfactant synergistic effect, changing the dynamic IFT pattern to an abrupt decrease to an IFT minimum (i.e., sometimes even drops to ultralow values) followed by a smooth increase until it converges with the static IFT. This behavior was reported by authors such as Liu et al. [20,21], who studied the dynamic IFT of different water/anionic + non-ionic surfactants/salt systems or Witthayapanyanon et al. [23], who performed measurements in mixtures containing water/anionic surfactant $/ \mathrm{NaCl}$.

The aforementioned experimental evidence served to propose different mechanisms to explain both the static and the dynamic IFT reduction phenomena. Two mechanisms were proposed to explain the static IFT reduction: (i) salinity reduces the solubility of surfactants in water, which forces them to migrate to the interface [30]; (ii) the salt ions can interact with the surfactant head groups and minimize the electrostatic interaction among them, which induces a closer packing of surfactants at the interface to allow additional surfactant molecules to fit at the interface [20,21]. Alternatively, the dynamic IFT reduction mechanism proposed assumes that surfactants are soluble in both the oil and the water phase. Then, the solubility of surfactants in water is lessened upon addition of salts, which promotes the diffusion of surfactants from the water to the oil phase through the oil/water interface. The minimum in the dynamic IFT is assumed to occur when the surfactant molecules that are diffusing to the oil phase, are close to the interface [31]. Finally, the IFT is increased again when they are at equilibrium in the oil bulk. In summary, all previous mechanisms were mainly deduced from experimental measurements, who relate the IFT reduction with an increased number of surfactants at the interface, based on the Gibbs adsorption isotherm [32]:

$$
d \gamma=-\sum_{i} \Gamma_{i} \mu_{i}
$$

91 where $\gamma$ is the IFT of the system and $\mu_{i}$ and $\Gamma_{i}$ are the chemical potential and the interfacial excess concentration of species $i$ at the interface for a given temperature. The ideal interface, represented by the Gibbs absorption isotherm, has an infinitesimal volume and is placed at the Gibbs dividing surface $(\sigma)$. For convenience, one should place $\sigma$ at the position that makes the $\Gamma_{i}$ of a reference component (e.g., water) equal to zero and refer 
96 other $\Gamma_{i}$ to that component (i.e., $\Gamma_{i}^{w}$ for water as reference). Finally, Eq. (1) can be

97 rearranged as:

$$
\Gamma_{i}^{w}=-\frac{1}{R T}\left(\frac{\partial \gamma}{\partial \ln \left(a_{i}\right)}\right)_{T, a_{j \neq i}}
$$

98 Notice that for diluted concentrations the activity $a_{i}$ in Eq. (2) can be taken simply as the 99 concentration. The expression indicates that the interfacial excess of a species $i$ can be 100 either negative or positive as a function of the interfacial behavior of this compound. If 101 this compound accumulates at the interface the value of $\Gamma_{i}^{w}$ is positive and the IFT is reduced upon addition of this compound to the solution. These types of species are known as surface active compounds. On the other hand, if a compound depletes from the interface the value of $\Gamma_{i}^{w}$ becomes negative and the IFT is increased upon addition of this compound.

106 The need of better understanding the interactions between salts and surfactants, motivated some simulation studies that combined ionic surfactants and salts [33-35]. From these works, it was observed that anionic surfactants, which have negatively charged head groups and usually $\mathrm{Na}^{+}$counterions, are capable of exchanging their $\mathrm{Na}^{+}$by divalent cations of the salt. This exchange is favored because divalent cations have more charge and interact more strongly with the charged head groups than $\mathrm{Na}^{+}$. Similarly, cationic surfactants, which have positively charged head groups and are commonly accompanied

$113 \mathrm{by}^{-}$counterions, are capable of exchanging their $\mathrm{Cl}^{-}$by divalent anions of the salt. Their 114 main conclusion was that these ionic exchanges modify the electrostatic interactions at 115 the interface, which perturb the interfacial molecular distributions. However, none these 116 works characterized the IFT reduction phenomena due to salt-surfactant synergistic 117 effects via molecular simulations.

118 To expand the knowledge in salt-surfactant interfacial phenomena, Molecular Dynamics 119 (MD) simulations on oil/water/surfactant/salt systems are performed, using pure 120 dodecane as model oil, three different chlorine salts (i.e., $\mathrm{NaCl}, \mathrm{CaCl}_{2}$ or $\mathrm{MgCl}_{2}$ ) and two 121 non-ionic surfactants: the Triethyleneglycol 1-dodecyl ether (i.e., $122 \mathrm{CH}_{3}\left(\mathrm{CH}_{2}\right)_{11}\left(\mathrm{OCH}_{2} \mathrm{CH}_{2}\right)_{3} \mathrm{OH}$ also known as $\left.\mathrm{C}_{12} \mathrm{E}_{3}\right)$, which is a linear surfactant with 12 $123 \mathrm{CH}_{\mathrm{x}}$ tail groups and a head with three polyoxyethylene units and an alcohol termination, 124 and triethyleneglycol 6-dodecyl ether (i.e., $\left(\mathrm{CH}_{3}\left(\mathrm{CH}_{2}\right)_{5}\right)\left(\mathrm{CH}_{3}\left(\mathrm{CH}_{2}\right)_{4}\right) \mathrm{CH}\left(\mathrm{OCH}_{2} \mathrm{CH}_{2}\right)_{3} \mathrm{OH}$ 125 alternatively named $\left.\left(\mathrm{C}_{6} \mathrm{C}_{5}\right) \mathrm{CE}_{3}\right)$. The latter is a version of the same surfactant but with a 
126 ramified tail. Thus $\left(\mathrm{C}_{6} \mathrm{C}_{5}\right) \mathrm{CE}_{3}$ and $\mathrm{C}_{12} \mathrm{E}_{3}$ share the same head group, and both tail groups

127 have the same molecular weight for the sake of evaluating the effect of the ramification

128 in the tail group. The purpose of these simulations is to explain the experimental trends

129 in the static IFT reduction and give an alternative perspective to this phenomenon from a

130 molecular point of view. Due to the MD simulations yielding equilibrium properties, only

131 salt-surfactant synergistic effects on the static IFT are evaluated, while the dynamic IFT

132 processes are not taken into account.

133 Although the correct characterization of the static salt-surfactant synergistic effect has a

134 significant impact in EOR (i.e., helping to lower the IFT and thus increasing production),

135 it is only one of the many phenomena involved in the complex process of oil recovery. In

136 fact, the presence of salts can also activate other mechanisms that hamper the oil

137 extraction. For example, it is well known that depending on the rock matrix, salt cations

138 can attach to the mineral surface and attract the negatively charged polar fraction of crude

139 oils to the rock, which ultimately reduce the wettability of the reservoir [36]. In that

140 situation, the effectivity of the recovery would be conditioned by the balance between all

141 the mechanisms activated in presence of salinity. This means that unless the static salt-

142 surfactant synergistic effect is capable defeating all other processes (i.e., by significantly

143 reducing the IFT) it might not be directly applicable to EOR. In any case, this effect is

144 present in any oil recovery process, so understanding it can help to unveil some of the

145 mechanisms occurring during oil recovery. 


\section{2. Computational methods}

148 MD simulations with classical force fields were performed by means of LAMMPS code

149 [37]. The initial simulation cell to calculate IFT consists on an orthorhombic box with 150 dimensions $L_{x}=L_{y}=80 \AA$ and $L_{z}=210 \AA$. Half of the simulation cell was filled with 151 water molecules at $\rho=0.997 \mathrm{~g} / \mathrm{cm}^{3}$ and the other half was filled with dodecane at $\rho=$ $1520.745 \mathrm{~g} / \mathrm{cm}^{3}$. Both values correspond to the experimental pure liquid densities at $T=300$ $153 \mathrm{~K}$ and $P=1 \mathrm{~atm}[38,39]$. The three different salts (i.e., $\mathrm{NaCl}, \mathrm{CaCl}_{2}$ or $\mathrm{MgCl}_{2}$ ) were 154 inserted only in the water phase at a 2.0 molal concentration. Notice that this 155 concentration is significantly higher than the average seawater salinity (i.e., $\sim 0.6 \mathrm{M}$ ) 156 typically used in waterflooding, or the optimum salinities commonly employed in low157 salinity/surfactant EOR. In fact, low-salinity is favored during oil recovery because it 158 helps surfactants to achieve ultralow dynamic IFT, and the wettability of the rocks is 159 increased in absence of salinity. However, in the present work, equilibrium MD 160 simulations of the liquid/liquid interface were conducted, where neither the dynamic 161 effects or the interactions with the rock are taken into consideration. Regarding static IFT 162 reductions, some experimental works seemed to show stronger effects at higher salinity 163 concentrations up to $2.0 \mathrm{M}[16,20-22]$. For this reason, three preliminary calculations were carried out to find the salinity concentration that maximized the static IFT reduction effect in the considered oil/water/surfactant systems: (i) no significant change on the equilibrium IFT was observed at 0.5 molal of $\mathrm{NaCl}$, (ii) a statistically meaningful reduction effect was detected at 2.0 molal of $\mathrm{NaCl}$ and (iii) the IFT was increased when calculated at 6.0 molal of $\mathrm{NaCl}$. Finally, the surfactants were added directly onto the water/oil interface to accelerate the equilibration of the system at a concentration below the CMC. The amount of surfactants simulated represents an interface with an interfacial excess $\Gamma_{i}^{W}=1.50 \mu \mathrm{mol} / \mathrm{m}^{2}$ (i.e., $110 \AA^{2} /$ molecule) and it has been chosen in consistency with the aforementioned experiments performed (i.e., below the CMC) $[11-13,15,16$,

$17318,22,23]$. The initial position and orientation of all molecules followed a uniform random distribution with the only restriction that molecules can only be generated in the respective regions detailed. Fig. 1 shows a typical simulation cell with a summary of all species involved in our simulations. 


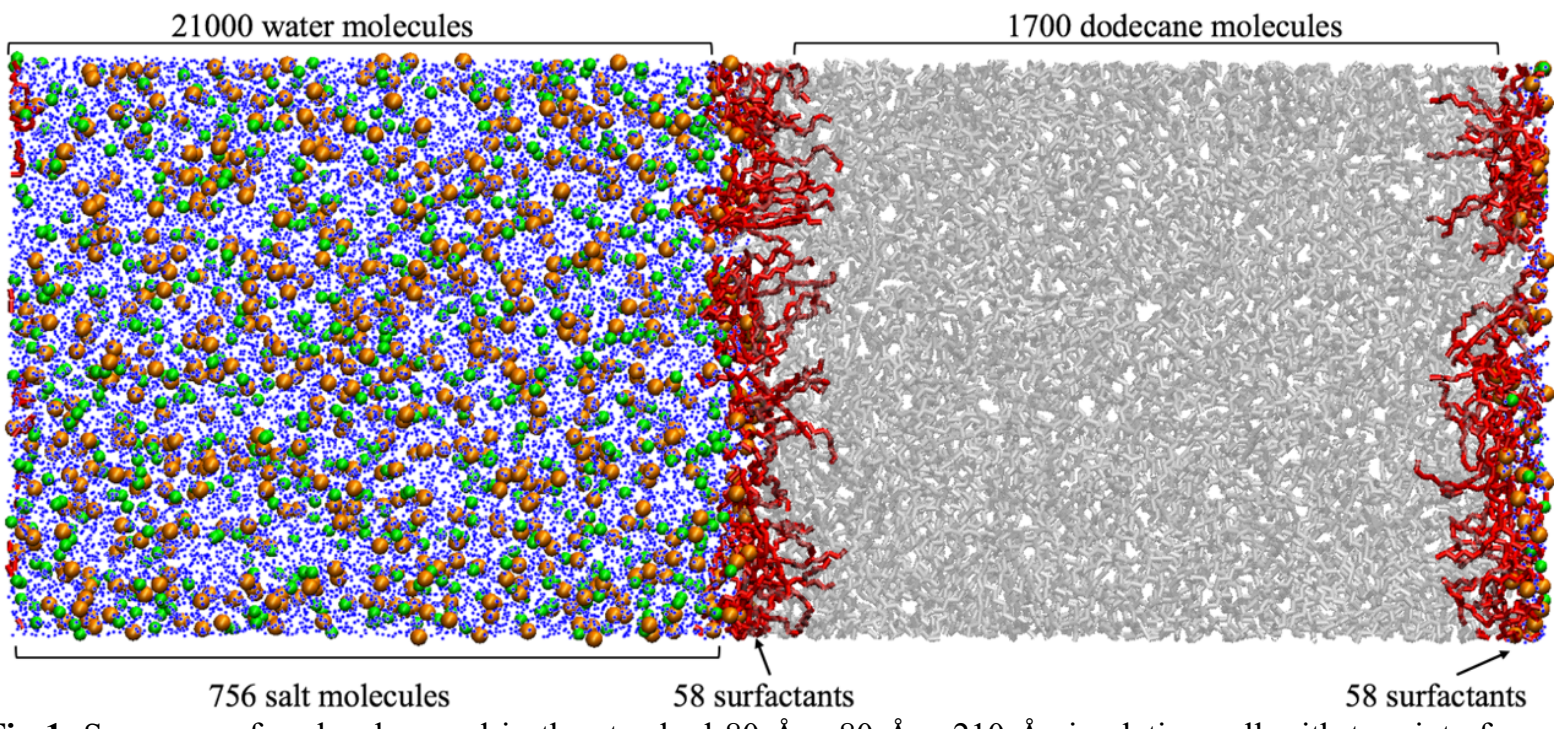

Fig 1. Summary of molecules used in the standard $80 \AA$ x $80 \AA$ x $210 \AA$ simulation cell with two interfaces. Dodecane and water molecules are represented by grey bonds and blue dots, respectively. Ionic salts are represented by spheres: the cation in orange and the anion in green. Finally, the surfactant molecules are displayed in red bonds accumulated at the interface.

178 The simulations were performed in three steps: first, the random creation of particles 179 required an initial minimization of the system to avoid molecular overlaps. Second, the 180 system was thermalized in the NVT ensemble, using first a Langevin thermostat [40] 181 during 20 ps followed by 100 ps with a Nosé-Hoover thermostat [41], a combination of 182 thermostats that was very efficient for thermal equilibration. Third, a Berendsen barostat 183 [42] was used to equilibrate the pressure during $500 \mathrm{ps,}$, while temperature was still 184 controlled by the Nosé-Hoover thermostat. The barostat only couples to the z-direction 185 of the simulation cell to keep interfacial area constant (i.e., NAP $\mathrm{T}$ T ensemble). Finally, 186 the Berendsen barostat was changed by a Nosé-Hoover barostat [43] to perform a time 187 evolution of $20 \mathrm{~ns}$. The thermostat and barostat constants were 0.2 and 1.0 ps respectively and the timestep for all simulation stages was $1 \mathrm{fs}$.

189 Block averages were extracted each $0.5 \mathrm{~ns}$ to monitor the evolution of the total energy 190 and interfacial tension of the system. In most simulations the equilibrium was reached 191 after $10 \mathrm{~ns}$ of evolution, and the range from 10 to $20 \mathrm{~ns}$ was used to calculate the 192 equilibrium IFT. For those calculations with longer equilibration times, 10 extra ns were 193 run to calculate the averages from this additional time. Also, to ensure that calculations 194 were fully converged, a single calculation was time evolved during 50 extra ns, obtaining 195 an equivalent value of IFT compared to the one calculated up to 20 ns. Finally, the 196 molecular distributions were calculated using the final 2 ns of the simulation. Notice that 
197 the large interfacial area (i.e., $80 \AA$ x $80 \AA$ ) employed in the simulations improve the 198 statistical significance of the molecular distributions. This means that averaging $2 \mathrm{~ns}$ is 199 enough to yield smooth density profiles as shown in the results section.

200 Intermolecular and intramolecular interactions of organic molecules were represented with the TraPPE-UA force field [44]. This force field considers that bonds are fixed at their equilibrium bond lengths, so we followed the standard recommendation of TraPPE developers and used the spring constants from AMBER force field [45] to allow molecular vibrations. Water molecules were reproduced using the rigid TIP3P force field [46], which were constrained to their equilibrium geometry through the SHAKE algorithm [47]. A validation stage of TraPPE-UA and TIP3P force fields was carried out to ensure that the models were correctly reproducing the properties of the surfactants and water. The validation is compiled in the Supplementary Material, where it is seen that the surfactants are well reproduced by TraPPE-UA. Similarly, the salt-surfactant synergistic effects identified in this work can also be seen with more sophisticated water models such as TIP4P/Ew [48]. However, the TIP4P model of water is computationally more expensive than a standard three-point model such as TIP3P. So, after ensuring that the latter is capable of capturing the salt-surfactant synergistic effect (see section S1 of the

214 Supplementary Material), it is selected due to computational efficiency. Finally, the ions 215 of salts (i.e., $\mathrm{Na}^{+}, \mathrm{Ca}^{2+}, \mathrm{Mg}^{2+}, \mathrm{Cl}^{-}$) are compounds hard to simulate by point charge models, as can be seen by the large amount of force fields developed by many authors on

217 the last years. To evaluate the effect of the force field on the calculated properties, 218 simulations with salts were performed with three different non-polarizable sets of 219 parameters: (i) the force field from Smith and Dang [49], whose parameters are implemented in CLAYFF; (ii) the force field from Àqvist [50], used in OPLS; and (iii) the force field from Beglov and Roux [51], found in the CHARMM force field. Crossed interactions between all species in this work are accounted through the standard LorentzBethelot mixing rules [52]. All pair interactions were calculated using a spherical cutoff of $14 \AA$ as recommended by TraPPE. Truncated potentials may induce important deviations to the calculated IFT values, as shown by several authors [53-57]. However, these deviations are usually systematic, and the relative trends are maintained, specially with similar systems. This study focuses on determining the qualitative effects of saltsurfactant interactions (i.e., the IFT is increased or decreased), so the proper application

229 of the tail corrections would yield to the same qualitative conclusion. Nevertheless, 
230 analytic tail corrections were included to the Lennard-Jones potential as recommended 231 by TraPPE [58]. Finally, the long-range coulombic interactions were computed by means 232 of the Particle-Particle/Particle-Mesh (PPPM) method [59].

233 IFT was calculated using the pressure tensor method of Kirkwood et al. [60, 61], which 234 relates this property with the difference between the normal $\left(P_{z z}\right)$ and tangential $\left(\frac{P_{x x}+P_{y y}}{2}\right)$ components of the pressure tensor (Eq. (3)). In this equation, $L_{z}$ corresponds to the length

236 of the simulation cell and the factor $1 / 2$ arises since the simulation cell exhibits two 237 interfaces. To calculate the statistical uncertainty of the results, three quasi-equivalent 238 replicas of the same dodecane/water/surfactant system were built, using the same number 239 of molecules, initial distribution, temperature and pressure. Then, all molecules are randomly rotated to generate a different initial state of the same system. The standard deviation of the three calculated IFT values are used as an estimate of the statistical uncertainty. Notice that all oil/water interfaces modelled in this work have a similar IFT, so the standard deviation of $\pm 0.8 \mathrm{dyn} / \mathrm{cm}$ calculated through this procedure is 244 transferable to all simulations.

$$
\gamma=\frac{L_{z}}{2}\left(P_{z z}-\frac{P_{x x}+P_{y y}}{2}\right)
$$

245 The distribution of molecules along the z-direction of the simulation cell (i.e., the number 246 density $\rho_{i}(z)$ ), was used to determine the accumulation or depletion of each species at the interface. To build them, the simulation cell was divided through the z-direction in bins of $1 \AA$ width, and the different number of particles in each bin was averaged over the last 2 ns of the simulation. From the z-distributions the interfacial excess was 250 calculated using Eq. (4) [32],

$$
\Gamma_{i}^{w}=\int_{a}^{b} \frac{\rho_{i}(z)-\rho_{i}^{g i b b s}(z)}{A} d z=\int_{a}^{b} \frac{\rho_{i}(z)}{A} d z-\frac{\bar{\rho}_{i}^{w} \cdot\left|\sigma^{w}-a\right|+\bar{\rho}_{i}^{o} \cdot\left|b-\sigma^{w}\right|}{A}
$$

251 where the integration limits $a$ and $b$ are the center of the water and oil bulks respectively, 252 and $\sigma^{w}$ is the position of the Gibbs dividing surface. The position of $\sigma^{w}$ was chosen to 253 make the interfacial excess of water equal to zero, which was selected as the reference 254 component. $\rho_{i}^{g i b b s}(z)$ corresponds to the density profile of component $i$ in a system with 255 two bulk phases split with an infinitesimally thin interface. In this ideal system the density 256 profile in each bulk phase is constant and equal to its the average density within the phase 
$257\left(\bar{\rho}_{i}{ }^{w}\right.$ for water and $\bar{\rho}_{i}{ }^{o}$ for oil). The water/dodecane reciprocal solubilities as well as the 258 salt/dodecane solubilities are very low, so the term $\bar{\rho}_{i}{ }^{\circ}$ can be neglected in our 259 simulations. Finally, this integral is normalized by the interface unit area $A$.

260 To assess how the addition of salts and surfactants affects molecular interactions, Radial 261 Distribution Functions (RDFs) between different molecular groups were calculated 262 through VMD code [62]. Also, the orientation of surfactants at the interface was analyzed 263 from the angle that both, the head and the tail groups, arrange with respect to the 264 interfacial perpendicular axis (i.e., the z-axis). 


\section{Results and discussion}

267

268

269

270

271

272

273

274

275

276

277

278

279

280

281

282

283

284

285

286

287

288

289

290

291

292

293

294

295

296

\subsection{IFT calculations and identification of the salt-surfactant synergistic effect}

We first performed MD simulations on pure water/dodecane systems with and without addition of salts at $300 \mathrm{~K}$ and $1 \mathrm{~atm}$. These calculations were used as a benchmark to test the accuracy of the methodology and the different force fields in comparison to the experimental and simulation data available on simple systems. In the case of water/dodecane system, an equilibrium IFT value of $50.0 \mathrm{dyn} / \mathrm{cm}$ was obtained, in good agreement with reported experimental data (i.e., $51.2-52.3 \mathrm{dyn} / \mathrm{cm}[63,64])$.

Salts increase the equilibrium IFT because they stay at the bulk of the water phase yielding negative surface excess concentrations, which increase IFT according to Eq. (1). According to IFT results reported in the bibliography on water/oil systems with $\mathrm{NaCl}$ [65-68], $\mathrm{CaCl}_{2}$ and $\mathrm{MgCl}_{2}$ [69], IFT increases almost linearly at concentrations up to 2 molal. From the experimental linear trends, we should expect that in the case of $\mathrm{NaCl}$ $\Delta \gamma=\gamma_{\text {salt }}-\gamma_{\text {no_salt }}$ values are between 3.0 to-and $3.6 \mathrm{dyn} / \mathrm{cm}$ at 2 molal. On the other hand, both divalent salts should increase IFT a similar amount between 6.0 to-and 6.5 $\mathrm{dyn} / \mathrm{cm}$ at the same concentration.

Table 1 shows the equilibrium IFT results for the different water/salt/dodecane models by using different force fields along with their respective $\Delta \gamma$ values. $\Delta \gamma_{\mathrm{NaCl}}$ is almost equivalent with the three force fields studied. CLAYFF and CHARMM increase IFT 3.7 $\mathrm{dyn} / \mathrm{cm}$ and $3.1 \mathrm{dyn} / \mathrm{cm}$, respectively, which is in good agreement with the expected values [65-69]. On the other hand, OPLS seems to slightly underestimate the $\mathrm{NaCl}$ effect showing a $\Delta \gamma_{\mathrm{NaCl}}=1.9 \mathrm{dyn} / \mathrm{cm}$. Although, the difference is small enough to consider these results comparable, other properties calculated in this work suggest that this underestimation might be important to reproduce some cross interactions (e.g., like surfactant- $\mathrm{Na}^{+}$interactions). These effects might be caused by a relatively low $\varepsilon$ and high $\sigma$ values of $\mathrm{Na}^{+}$OPLS parameters compared to the other force fields, which makes $\mathrm{Na}^{+}$ to be more repulsive and to have less attractive crossed interactions. In the case of divalent salts, both CLAYFF and OPLS force fields are very similar, but they both give a higher $\Delta \gamma$ value for $\mathrm{CaCl}_{2}$ than for $\mathrm{MgCl}_{2}$ (i.e., $\Delta \gamma_{\mathrm{CaCl}_{2}}=7.1 \mathrm{dyn} / \mathrm{cm}$ and $\Delta \gamma_{\mathrm{MgCl}_{2}}=5.6 \mathrm{dyn} / \mathrm{cm}$ for CLAYFF; and $\Delta \gamma_{\mathrm{CaCl}_{2}}=7.2 \mathrm{dyn} / \mathrm{cm}$ and $\Delta \gamma_{\mathrm{MgCl}_{2}}=4.6 \mathrm{dyn} / \mathrm{cm}$ for OPLS). On the other hand, with CHARMM force field the IFT increase is equivalent for the three salts 
297 studied (i.e., $\Delta \gamma_{\mathrm{NaCl}}=3.1 \mathrm{dyn} / \mathrm{cm}, \Delta \gamma_{\mathrm{CaCl}_{2}}=2.5 \mathrm{dyn} / \mathrm{cm}$ and $\Delta \gamma_{\mathrm{MgCl}_{2}}=2.5 \mathrm{dyn} / \mathrm{cm}$ ).

298 From these results we can extract three premises: (i) $\mathrm{NaCl}$ is well reproduced with all 299 force fields but OPLS might be slightly underestimating the interactions between the $\mathrm{Na}^{+}$ 300 cation and other species; (ii) the divalent salts reproduced with CHARMM parameters 301 give IFTs too low when compared to experimental results [69]; and (iii) CLAYFF force 302 field seems give the best general representation of the three salts.

Table 1.

Equilibrium IFT results (in dyn/cm) for the water/salt/dodecane systems studied at $300 \mathrm{~K}$ and $1 \mathrm{~atm}$ using the three different force fields for salts. The values between parentheses correspond to the IFT change (i.e., $\Delta \gamma=\gamma_{\text {salt }}-\gamma_{\text {no_salt }}$ ). The estimated uncertainties in these simulations are $\pm 0.8 \mathrm{dyn} / \mathrm{cm}$.

\begin{tabular}{|c|c|c|c|c|c|}
\hline & Modelled system & No salt & $\mathrm{NaCl}$ & $\mathrm{CaCl}_{2}$ & $\mathrm{MgCl}_{2}$ \\
\hline \multirow{3}{*}{ 岌 } & Oil/water/salt & 50.0 & $53.7(3.7)$ & $57.1(7.1)$ & $55.6(5.6)$ \\
\hline & $+\mathrm{C}_{12} \mathrm{E}_{3}$ & 39.0 & $38.7(-0.3)$ & $45.4(6.4)$ & $43.4(4.4)$ \\
\hline & $+\left(\mathrm{C}_{6} \mathrm{C}_{5}\right) \mathrm{CE}_{3}$ & 39.0 & $35.5(-3.5)$ & $43.6(4.6)$ & $43.7(4.7)$ \\
\hline \multirow{3}{*}{$\frac{\pi}{0}$} & Oil/water/salt & 50.0 & $51.9(1.9)$ & $57.2(7.2)$ & $54.6(4.6)$ \\
\hline & $+\mathrm{C}_{12} \mathrm{E}_{3}$ & 39.0 & $40.9(1.9)$ & $43.1(4.1)$ & $44.0(5.0)$ \\
\hline & $+\left(\mathrm{C}_{6} \mathrm{C}_{5}\right) \mathrm{CE}_{3}$ & 39.0 & $40.0(1.0)$ & $42.4(3.4)$ & $41.7(2.7)$ \\
\hline \multirow{3}{*}{ 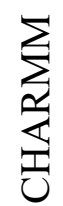 } & Oil/water/salt & 50.0 & $53.1(3.1)$ & $52.5(2.5)$ & $52.5(2.5)$ \\
\hline & $+\mathrm{C}_{12} \mathrm{E}_{3}$ & 39.0 & $39.1(0.1)$ & $43.0(4.0)$ & $41.7(2.7)$ \\
\hline & $+\left(\mathrm{C}_{6} \mathrm{C}_{5}\right) \mathrm{CE}_{3}$ & 39.0 & $36.9(-2.1)$ & $41.4(2.4)$ & $41.0(2.0)$ \\
\hline
\end{tabular}

303

304 We would like to note that, even though force fields for salts do not usually use IFT as a target function for fitting, the results obtained with the three force fields are reasonably good. Also, the results obtained in our simulations do not state that CLAYFF is a better force field than OPLS or CHARMM, but simply that in our system the least deviation

308 from the experimental results seems to be obtained by using CLAYFF parameters.

309 However, if other properties or systems were assessed, this could no longer be the case.

310 For the sake of simplicity, figures will show all the observed effects using only CLAYFF

311 parameters for salts, and the discussion among the different force fields will be reduced

312 to the minimum. All the information comparing the three force field calculations will be 313 available in the Supplementary Material.

314 After this preliminary evaluation, we assessed the effect of salt addition onto a 315 water/surfactant/dodecane system using low concentrations of a linear $\left(\mathrm{C}_{12} \mathrm{E}_{3}\right)$ and a 
316 ramified $\left(\left(\mathrm{C}_{6} \mathrm{C}_{5}\right) \mathrm{CE}_{3}\right)$ non-ionic surfactant. The pure water/dodecane IFT was reduced

317 from the previous value of $50.0 \mathrm{dyn} / \mathrm{cm}$ to $39.0 \mathrm{dyn} / \mathrm{cm}$ when adding either the linear or

318 the ramified surfactant. In these calculations all of the surfactant molecules stay at the

319 interface with their polar heads facing the water phase and their tail groups oriented

320 towards the dodecane phase.

321 The addition of salt upon these systems do not show the same trends that the pure water/dodecane system. When using CLAYFF force field and the linear $\mathrm{C}_{12} \mathrm{E}_{3}$ surfactant is present, the IFT is not increased by $\mathrm{NaCl}$ as before, denoting a cooperative effect between the surfactant and $\mathrm{NaCl}$, which produces a small IFT reduction $\left(\Delta \gamma_{\mathrm{NaCl}}=-0.3\right.$ dyn/cm). Additionally, if $\mathrm{NaCl}$ is into a system containing the ramified $\left(\mathrm{C}_{6} \mathrm{C}_{5}\right) \mathrm{CE}_{3}$ surfactant, this cooperative effect is enhanced, and shows a larger reduction in the IFT value $\left(\Delta \gamma_{\mathrm{NaCl}}=-3.5 \mathrm{dyn} / \mathrm{cm}\right)$. On the other hand, the interactions of these surfactants with divalent cations are weaker, and the calculated $\Delta \gamma$ does not achieve negative values. Even though divalent cations do not reduce the IFT, the $\Delta \gamma$ obtained is lower in presence of surfactants than in the pure dodecane/water system, which suggests that a weak interaction is still present on these systems. As an example, $\mathrm{CaCl}_{2}$ in absence of surfactant gives a $\Delta \gamma_{\mathrm{CaCl}_{2}}=7.1 \mathrm{dyn} / \mathrm{cm}$, whereas with the linear surfactant is $\Delta \gamma_{\mathrm{CaCl}_{2}}=6.4 \mathrm{dyn} / \mathrm{cm}$ and with the ramified surfactant is $\Delta \gamma_{\mathrm{CaCl}_{2}}=4.6 \mathrm{dyn} / \mathrm{cm}$. The interaction is even weaker with $\mathrm{MgCl}_{2}$, in which all $\Delta \gamma$ values are relatively similar. As a summary, the results obtained suggests that salts can interact with surfactants following the order of $\mathrm{NaCl}>$

$336 \mathrm{CaCl}_{2}>\mathrm{MgCl}_{2}$ even when they do not explicitly show an absolute IFT reduction.

337 Additionally, regardless of the salt used, the values of $\Delta \gamma$ tend to be ordered from the 338 lowest to the highest as: $\Delta \gamma_{\text {ramified }}<\Delta \gamma_{\text {linear }}<\Delta \gamma_{\text {no_surfact }}$, which suggest that the 339 ramified surfactant is the molecule that interacts more strongly with salt ions, followed 340 by the linear surfactant.

341 The same trends observed without surfactant, regarding IFT, are preserved in these 342 simulations: the IFT reduction with $\mathrm{NaCl}$ is achieved also with CHARMM force field but 343 not with OPLS, where the salt-surfactant interaction is the weakest. Similarly, divalent 344 salts modelled with OPLS follow similar trends than CLAYFF, but the salt-surfactant 345 interactions reproduced with CHARMM are almost inexistent.

346 The previous calculations suggest that the IFT in our system with surfactants is affected 347 mainly by the presence of $\mathrm{NaCl}$ and secondarily by $\mathrm{CaCl}_{2}$. The currently proposed 
mechanisms (explained before) assume that IFT is reduced because, somehow, the concentration of surfactant is increased at the interface. However, in our setup all surfactant molecules are already accumulated at the interface before adding the salt, so the effect must be explained from other molecular rearrangements, orientations, or microscopical interactions. In this sense, in the following sections we will analyze different factors that could be affecting the IFT and comparing the effects depending on the salt used.

\subsection{Interfacial excess concentrations and z-distributions:}

According to Eq. (1), the $\gamma$ of a system depends on the interfacial excess of each added species. This magnitude can be positive if the compound accumulates at the interface, whereas it can be negative if it avoids the interface and stays at the bulk of its phase. We calculated the interfacial excess of both salt and surfactants from the z-distributions at equilibrium by means of Eq. (4), using as integration limits the center of each liquid phase. As all surfactant molecules stay at the interface for the whole simulation time, their density at the bulk is equal to 0 , and the interfacial excess is the same for all calculations (i.e., $\rho_{i}^{g i b b s}(z)=0$ and $\left.\Gamma_{i}^{w}=1.50 \mu \mathrm{mol} / \mathrm{m}^{2}\right)$.

For the water/salt/dodecane systems (i.e., without surfactants), the interfacial excess of salts is always negative, which justifies the increase of the IFT. According to our results, the IFT change with the interfacial excess cannot be directly compared between different species. For example, with CLAYFF force field (Table 2), both $\mathrm{Ca}^{2+}$ and $\mathrm{Cl}^{-}$have a interfacial excess of $\Gamma_{+}^{w}=-0.45 \mu \mathrm{mol} / \mathrm{m}^{2}$ and $\Gamma_{-}^{w}=-0.89 \mu \mathrm{mol} / \mathrm{m}^{2}$ respectively, whereas $\mathrm{Mg}^{2+}$ and $\mathrm{Cl}^{-}$have $\Gamma_{+}^{w}=-0.92 \mu \mathrm{mol} / \mathrm{m}^{2}$ and $\Gamma_{-}^{w}=-1.83 \mu \mathrm{mol} / \mathrm{m}^{2}$ respectively. If we only considered the interfacial excess of $\mathrm{CaCl}_{2}$ and $\mathrm{MgCl}_{2}$ we would conclude that $\mathrm{MgCl}_{2}$ is farther from the interface than $\mathrm{CaCl}_{2}$, so the change in IFT when adding $\mathrm{MgCl}_{2}$ should be larger. However, with all the checked force fields $\Delta \gamma_{\mathrm{CaCl}_{2}}>\Delta \gamma_{\mathrm{MgCl}_{2}}$, or at least equal, as it can be seen in Table 1.

The interfacial excess of salts is generally increased by the presence of surfactants following the order $\Gamma_{\text {salt }}^{w}($ no_surfact. $)<\Gamma_{\text {salt }}^{w}\left(\mathrm{C}_{12} \mathrm{E}_{3}\right)<\Gamma_{\text {salt }}^{w}\left(\left(\mathrm{C}_{6} \mathrm{C}_{5}\right) \mathrm{CE}_{3}\right)$. This implies that the polar head groups of surfactants are interacting with the ions of salts, attracting them to the interface. Also, the ramified surfactant is more effective than the 
379 linear surfactant as it can be seen with all studied force fields in Table 2. These trends 380 correlate with the respective values of $\Delta \gamma$ obtained in section 3.1, suggesting again that $381\left(\mathrm{C}_{6} \mathrm{C} 5\right) \mathrm{CE}_{3}>\mathrm{C}_{12} \mathrm{E}_{3}$ and $\mathrm{NaCl}>\mathrm{CaCl}_{2}>\mathrm{MgCl}_{2}$ for the salt-surfactant synergistic effects 382 in the studied system. Notice from Table 2 that the addition of $\mathrm{NaCl}$ onto systems with 383 these non-ionic surfactants can even yield positive interfacial excesses. The calculations 384 with positive $\Gamma_{i}^{w}$ are the same ones that gave negative or almost zero values of $\Delta \gamma$. Finally, 385 similar trends regarding the other force fields are shown again, producing weaker effects 386 for the $\mathrm{NaCl} / \mathrm{OPLS}$ and $\mathrm{CaCl}_{2} / \mathrm{MgCl}_{2} / \mathrm{CHARMM}$ force field combinations.

Table 2.

Gibbs interfacial excess concentrations in $\mu \mathrm{mol} / \mathrm{m}^{2}$ for the cation $\left(\Gamma_{+}^{\mathrm{w}}\right)$ and the anion $\left(\Gamma_{-}^{\mathrm{w}}\right)$ of all studied systems at $300 \mathrm{~K}$ and $1 \mathrm{~atm}$.

\begin{tabular}{|c|c|c|c|c|c|c|c|}
\hline & \multirow{2}{*}{ Modelled system } & \multicolumn{2}{|c|}{$\mathrm{NaCl}$} & \multicolumn{2}{|c|}{$\mathrm{CaCl}_{2}$} & \multicolumn{2}{|c|}{$\mathrm{MgCl}_{2}$} \\
\hline & & $\Gamma_{+}^{w}$ & $\Gamma_{-}^{w}$ & $\Gamma_{+}^{w}$ & $\Gamma_{-}^{w}$ & $\Gamma_{+}^{w}$ & $\Gamma_{-}^{w}$ \\
\hline \multirow{3}{*}{ 岌 } & Oil/water/salt & -0.83 & -0.82 & -0.45 & -0.89 & -0.92 & -1.83 \\
\hline & $+\mathrm{C}_{12} \mathrm{E}_{3}$ & 0.20 & 0.23 & -0.29 & -0.57 & -0.89 & -1.75 \\
\hline & $+\left(\mathrm{C}_{6} \mathrm{C}_{5}\right) \mathrm{CE}_{3}$ & 0.22 & 0.29 & -0.19 & -0.46 & -0.76 & -1.51 \\
\hline \multirow{3}{*}{$\frac{n}{0}$} & Oil/water/salt & -0.38 & -0.40 & -0.85 & -1.64 & -0.99 & -1.99 \\
\hline & $+\mathrm{C}_{12} \mathrm{E}_{3}$ & -0.51 & -0.54 & -0.17 & -0.34 & -0.61 & -1.12 \\
\hline & $+\left(\mathrm{C}_{6} \mathrm{C}_{5}\right) \mathrm{CE}_{3}$ & -0.31 & -0.30 & -0.14 & -0.29 & -0.45 & -0.95 \\
\hline \multirow{3}{*}{ 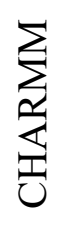 } & Oil/water/salt & -0.54 & -0.51 & -0.54 & -1.12 & -1.07 & -2.11 \\
\hline & $+\mathrm{C}_{12} \mathrm{E}_{3}$ & 0.25 & 0.31 & -0.58 & -1.19 & -1.19 & -2.40 \\
\hline & $+\left(\mathrm{C}_{6} \mathrm{C}_{5}\right) \mathrm{CE}_{3}$ & 0.47 & 0.44 & -0.66 & -1.35 & -0.93 & -1.87 \\
\hline
\end{tabular}

387

388 In Fig. 2 one can see the z-distributions of all studied systems. In absence of surfactant 389 (Fig. 2a-c) the concentration of the three salts in dodecane is zero and then, it starts 390 increasing in the water phase until the bulk concentration. In these systems each $\mathrm{Na}^{+}$ 391 cation is paired with a single $\mathrm{Cl}^{-}$anion in the whole simulation cell, whereas $\mathrm{Ca}^{2+}$ and $392 \mathrm{Mg}^{2+}$ are paired with two $\mathrm{Cl}^{-}$due to its divalent charge. However, if we add a non-ionic 393 surfactant onto a cell with $\mathrm{NaCl}$ (Fig. 2d and Fig. 2g), the salt z-distribution at the 394 oil/water interface changes significantly. Two very well-defined peaks (per interface) 395 appear in the distribution: the first is a $\mathrm{Na}^{+}$peak very close to the interface that suggest 396 that the polar head groups of the surfactant are attracting the cation, increasing the 397 interfacial excess and reducing the IFT. The second is the most intern $\mathrm{Cl}^{-}$peak, 
398 approximately $5 \AA$ away from the $\mathrm{Na}^{+}$peak, facing the water bulk. This group of ions do 399 not interact with the surfactants as strongly as $\mathrm{Na}^{+}$, so they have been dragged towards 400 the interface by the coulombic force of its counterions. These differences in interaction 401 strengths induce a different ionic distribution for $\mathrm{Na}^{+}$and for $\mathrm{Cl}^{-}$at the interface, 402 effectively producing an electric double layer, which makes the interface more polar and 403 probably also affects the IFT (i.e., see the magnifications of Fig. $2 \mathrm{~d}$ and Fig. $2 \mathrm{~g}$ ). The 404 excess concentrations of divalent cations are also increased by the presence of surfactant 405 (Table 2), but their interaction is much weaker, and their distributions do not change 406 significantly (i.e., no differences can be appreciated in Fig. 2b-c Fig. 2e-f and Fig. 2h-g 407 due to weaker salt-surfactant interactions). 


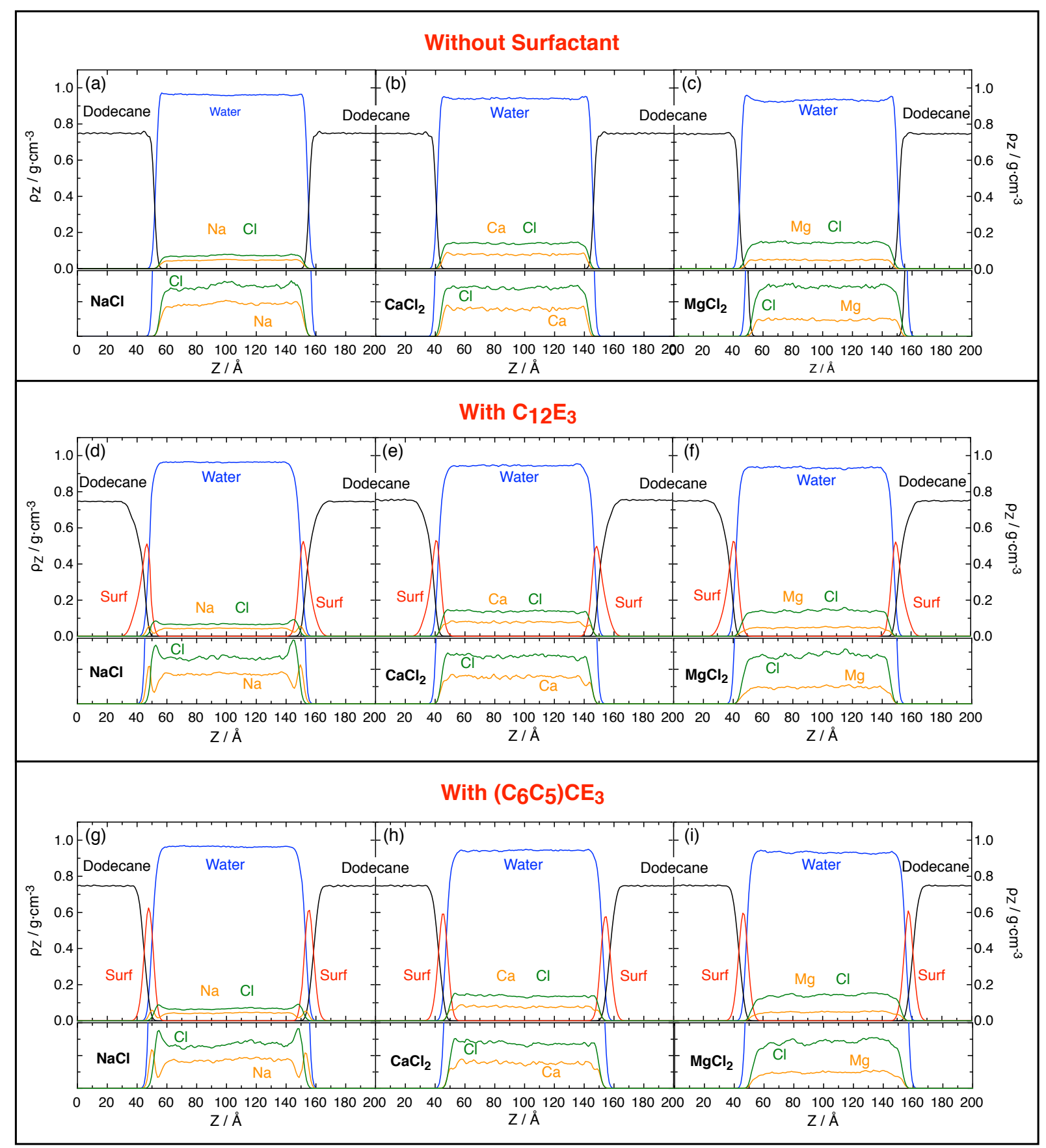

Fig. 2. The z-distributions of water/salt/dodecane systems, with and without surfactant, at equilibrium. The top row (i.e., (a), (b) and (c)) represents the system only with salt (i.e., $\mathrm{NaCl}, \mathrm{CaCl}_{2}$ and $\mathrm{MgCl}_{2}$, respectively and without surfactant); the mid row (i.e., (d), (e) and (f)) shows the distributions of the systems with the linear $\mathrm{C}_{12} \mathrm{E}_{3}$ surfactant and the three salts; and the bottom row (i.e., (g), (h) and (i)) contains the equilibrium configurations of systems with the ramified $\left(\mathrm{C}_{6} \mathrm{C}_{5}\right) \mathrm{CE}_{3}$ surfactant and the salts. Below each subplot there is a zoom to see more clearly the salt distribution, in which surfactant and dodecane distributions were erased for clarity. In all plots blue lines correspond to water, black lines to dodecane, red lines to the surfactant and orange/green lines to the cation/anion of each salt, respectively. The results shown are calculated with CLAYFF force field for salts at $300 \mathrm{~K}$ and $1 \mathrm{~atm}$.

409 The obtained results in this section show that cations can interact with the surfactant head 410 groups, which affect the distributions of salt ions at the interface. These interactions are 
411 stronger in salts that showed the strongest IFT reductions (e.g., the case of $\mathrm{Na}^{+}$in Fig. $2 \mathrm{~d}$ 412 and Fig. 2g). In these situations, the interface even becomes polarized by an electric 413 double layer of $\mathrm{Na}^{+}$and $\mathrm{Cl}^{-}$ions. To conclude, there is a correlation between the 414 reorganization of interfacial cations and the IFT reduction effect. However, this is not 415 enough to explain the salt-surfactant synergistic effect. Specifically, the IFT reduction 416 also depends on the surfactant used, as suggested by the results compiled in Table 1 and 417 Table 2.

418 This IFT reduction is relatively weak when compared to the required synergistic effects 419 needed for efficient EOR. However, the effect seen in this work is comparable to some 420 of the abovementioned studies that use different surfactants and brines and can shed some 421 light in explaining previously published experiments. Some examples are: Al-Sahhaf et 422 al. [11] found IFT reductions of $2-3 \mathrm{dyn} / \mathrm{cm}$ when adding salt to both a cationic and an 423 anionic surfactant, or Fainermann et al. [14], who showed that $\mathrm{NaCl}$ was capable of 424 reducing the IFT of an oil/water/surfactant system between $5 \mathrm{dyn} / \mathrm{cm}$ and $18 \mathrm{dyn} / \mathrm{cm}$ 425 depending on the surfactant concentration. The synergistic effect with non-ionic 426 surfactants $+\mathrm{NaCl}$ has also been experimentally described close to the CMC by Bera et 427 al. [12], even achieving resulting IFTs lower than $0.1 \mathrm{dyn} / \mathrm{cm}$.

\subsection{Surfactant orientation at the interface}

430 Normally, the IFT of a system is reduced when compounds accumulate at the interface, 431 but some works have proven that the orientation of some species can also be an important 432 aspect to consider. In fact, the orientation of liquid crystals dramatically changes the 433 interfacial tension (i.e., the reader is redirected to Refs. [70, 71] for a recent review of this 434 topic). To evaluate the effect that salt ions produce towards surfactant orientation the 435 angle between the head and the tail groups with respect to the perpendicular of the 436 interfacial plane (i.e., the z-axis in our simulation cell) was analyzed. Both non-ionic 437 surfactants have relatively long heads and tails, so the orientation of each group was 438 determined separately, as it can be seen in Fig. 3. The director vector of the head group 439 was calculated, from principal component analysis, considering the molecular axis that 440 goes in the direction from the first oxygen atom (i.e., the closest to the tail group) to the 441 terminal $\mathrm{OH}$ group. Similarly, the tail group vector was chosen as the molecular axis that 442 follows the direction from the first atom of the tail (i.e., the $\mathrm{CH}_{\mathrm{x}}$ bonded to the first 
443 oxygen) to the terminal $\mathrm{CH}_{3}$ group. For the case of the ramified surfactant, each tail was 444 considered separately. Moreover, to get information about the conformation of the 445 surfactants at the interface, we computed the angle formed between the different groups 446 within the same molecule (i.e., the head-tail angle for both surfactants, and the tail-tail 447 angle for the ramified surfactant).

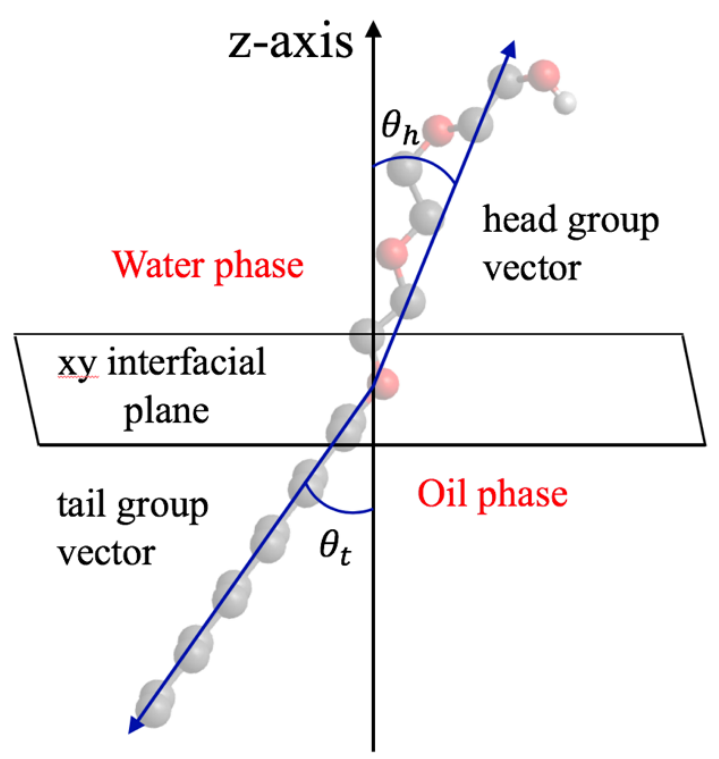

Fig. 3. Intramolecular reference framework used for angular distributions of the tail and the head groups of surfactant molecules at the interface.

Fig. 4 shows the angular distribution of head and tail groups for both the linear surfactant (Fig. 4a-c) and the ramified surfactant (Fig. 4d-f) in absence and presence of salt. It is worth noting that in all simulations the head groups are facing the water phase, whereas the tail groups are facing the oil phase. In absence of salt, the head groups of both surfactants (Fig. 4a and Fig. 4d) have the highest probability to be oriented almost parallel to the interfacial plane (i.e., between $70^{\circ}$ and $90^{\circ}$ with respect to the perpendicular axis). On the other hand, the tail groups for the linear $\mathrm{C}_{12} \mathrm{E}_{3}$ (Fig. 4b) show a uniform random distribution at angles between $40^{\circ}$ and $90^{\circ}$ with respect to the z-axis, whereas the tail groups of the ramified $\left(\mathrm{C}_{6} \mathrm{C}_{5}\right) \mathrm{CE}_{3}$ (Fig. $\left.4 \mathrm{e}\right)$ have a large probability to be oriented between $60^{\circ}$ and $90^{\circ}$. The obtained results show that both surfactants are positioned relatively planar with respect to the interface, specially the surfactant head groups and the tail groups of the ramified surfactant. This means that the ramified surfactant should occupy more interfacial area than the linear surfactant, because it spreads more through the interface rather than pointing towards the dodecane bulk. This effect was also observed 
463 in the z-distributions of Fig. 2, where the ramified surfactant distribution peak is thinner 464 than the one for the linear surfactant. Finally, the angle between the head and the tail 465 groups for both $\mathrm{C}_{13} \mathrm{E}_{3}$ (Fig. 4c) forms a very wide distribution with the maximum of 466 probability located at values from $80^{\circ}$ to $130^{\circ}$ approximately, which suggests that the 467 surfactant is significantly bent (i.e., $180^{\circ}$ would be completely linear). On the other hand, $468\left(\mathrm{C}_{6} \mathrm{C}_{5}\right) \mathrm{CE}_{3}$ presents an even flatter distribution with similar probabilities between $30^{\circ}$ and $469140^{\circ}$. Notice that all distributions shown here are relatively flat because surfactant 470 concentration is very low. This fact implies that surfactant molecules are relatively free 471 at the interface and their orientation is not restricted by the presence of other surface472 active molecules.

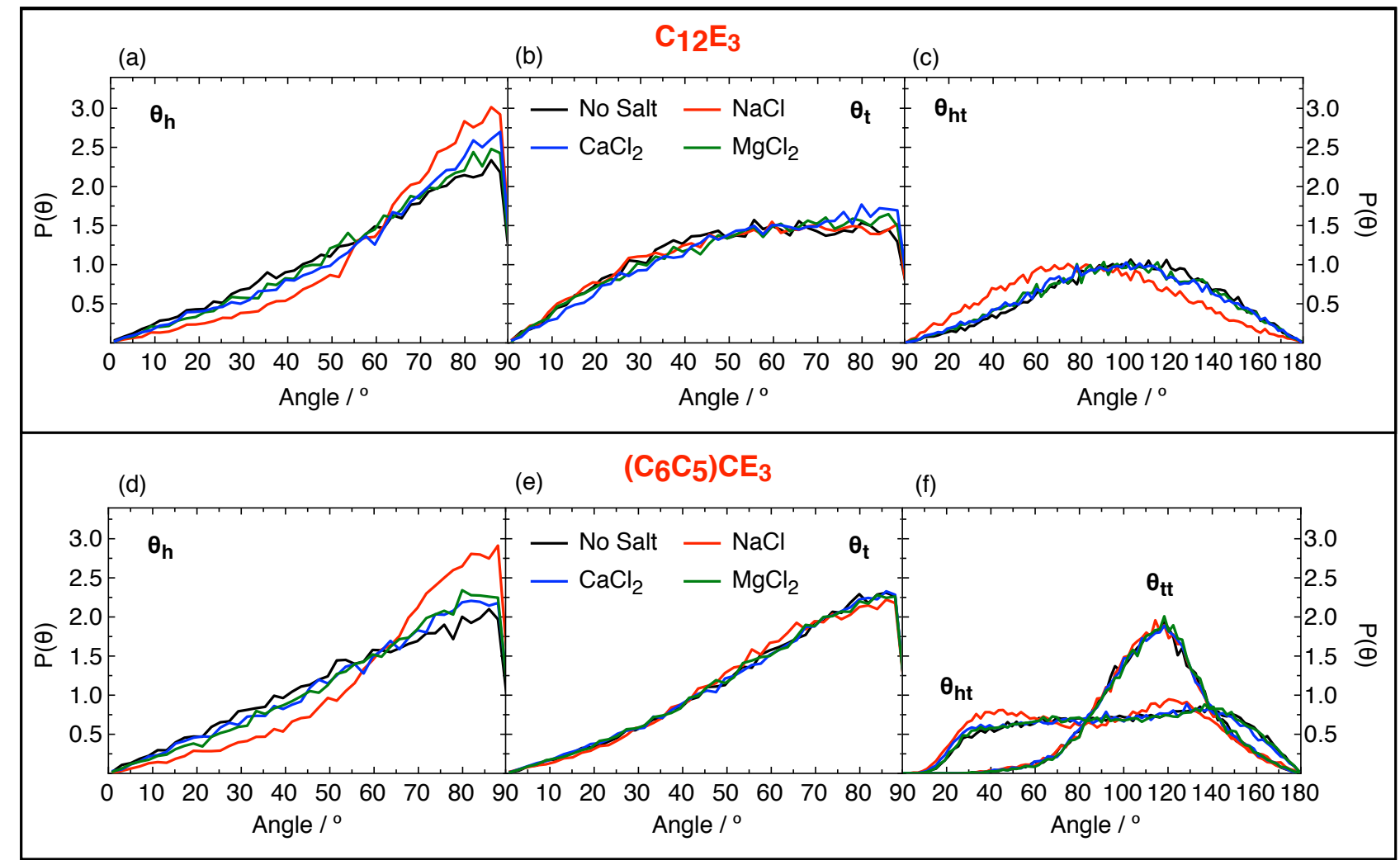

Fig. 4. Probability angular distributions for different groups in the linear surfactant $\left(\mathrm{C}_{12} \mathrm{E}_{3}\right)$ and in the ramified surfactant $\left(\left(\mathrm{C}_{6} \mathrm{C}_{5}\right) \mathrm{CE}_{3}\right)$. The distribution of head groups $\left(\theta_{\mathrm{h}}\right)$ is shown in (a) and $(\mathrm{d})$, the distribution of tail groups $\left(\theta_{t}\right)$ is depicted in (b) and (e) and the head/tail $\left(\theta_{\mathrm{ht}}\right)$ and tail/tail $\left(\theta_{\mathrm{tt}}\right)$ angles are compiled in (c) and (f). The results correspond to the simulations performed with CLAYFF force field for salts at $300 \mathrm{~K}$ and $1 \mathrm{~atm}$.

474 The addition of salt onto the system with surfactants does not affect the distribution of 475 any tail groups (i.e., no effects are seen in Fig. 4b and Fig 4e). However, the peak between $47670^{\circ}$ and $90^{\circ}$ of the head group distribution is increased in the order $\mathrm{NaCl}>\mathrm{CaCl}_{2}>\mathrm{MgCl}_{2}$, 477 as shown in Fig. 4a and Fig. 4d. Namely, this probability is increased around a 30\% with 
both surfactants when adding $\mathrm{NaCl}$. This implies again that cations are able to interact with the surfactant head groups and, in average, make them become more planar towards the interface. In general, there is a clear correlation between the amplitude of this effect and the IFT reduction, which is more noticeable when adding $\mathrm{NaCl}$. Additionally, as the head group angle is changing, the angle between the head and the tail groups also changes. In particular, the surfactants become more bent by effect of salts.

According to the results shown in this section, the orientations of surfactant head and tail groups at low interfacial concentration are relatively planar. In fact, the highest probability in their angular distribution with respect the z-axis for both groups is over $45^{\circ}$. Also, the ramified surfactant tail occupies more interfacial area than its linear counterpart, which implies that it should be more effective in covering the water/oil interface and in reducing the IFT. On the other hand, the distribution of head groups in both surfactants is affected similarly by salinity. The head groups became more planar with respect to the interface after the addition of $\mathrm{NaCl}$, but as the ramified surfactant tail occupies more interfacial area it reduces the IFT more effectively. Finally, tail groups were not affected by the presence of salt.

\subsection{Radial distribution functions}

496 We have seen in the previous sections that both, surfactants and salts are forcing each other to rearrange at the interface. In fact, we have observed a correlation between the amplitude of the IFT reduction effect in surfactant/ $\mathrm{NaCl}$ mixtures (Table 1), the formation of the electric double layer by interfacial $\mathrm{Na}^{+}$and $\mathrm{Cl}^{-}$ions (Table 2 and Fig. 2) and the bending of surfactant head groups (Fig. 4). To know more about the interactions that drive these general patterns we have calculated the RDFs between different molecular groups (i.e., the water, the salt ions, the dodecane and the surfactant head and tail groups) and compared their interactions in absence and presence of salt.

504 First, we compared how the RDF between water and dodecane molecules close to the interface was affected by salinity for systems with and without surfactants. We have considered all atoms in dodecane and only $\mathrm{O}$ atoms for water when building the pair-wise

507 distributions. The system without surfactant (Fig. 5a) shows an exactly equivalent 508 distribution regardless of the salt used, which means that salinity does not affect 
water/dodecane interactions. However, the systems with both the linear (Fig. 5b) and the

510 ramified (Fig. 5c) surfactants with $\mathrm{NaCl}$, show a slightly lower RDF. This fact implies

511 that dodecane and water are, in average, farther away from each other because surfactants

512 occupy more interfacial area. This relegates dodecane and water molecules to their

513 respective bulks reducing the RDF. Specifically, the dodecane/water RDFs when

514 including surfactants and $\mathrm{NaCl}$ are reduced approximately a $15 \%$ and a $30 \%$ for the linear

515 and ramified surfactants, respectively. Notice that $\mathrm{Ca}^{2+}$ is also able to separate the

516 dodecane and water phases with the linear surfactant (Fig. 5b), as well as it was also able

517 to affect the orientation of the linear surfactant at the interface (Fig. 4a).

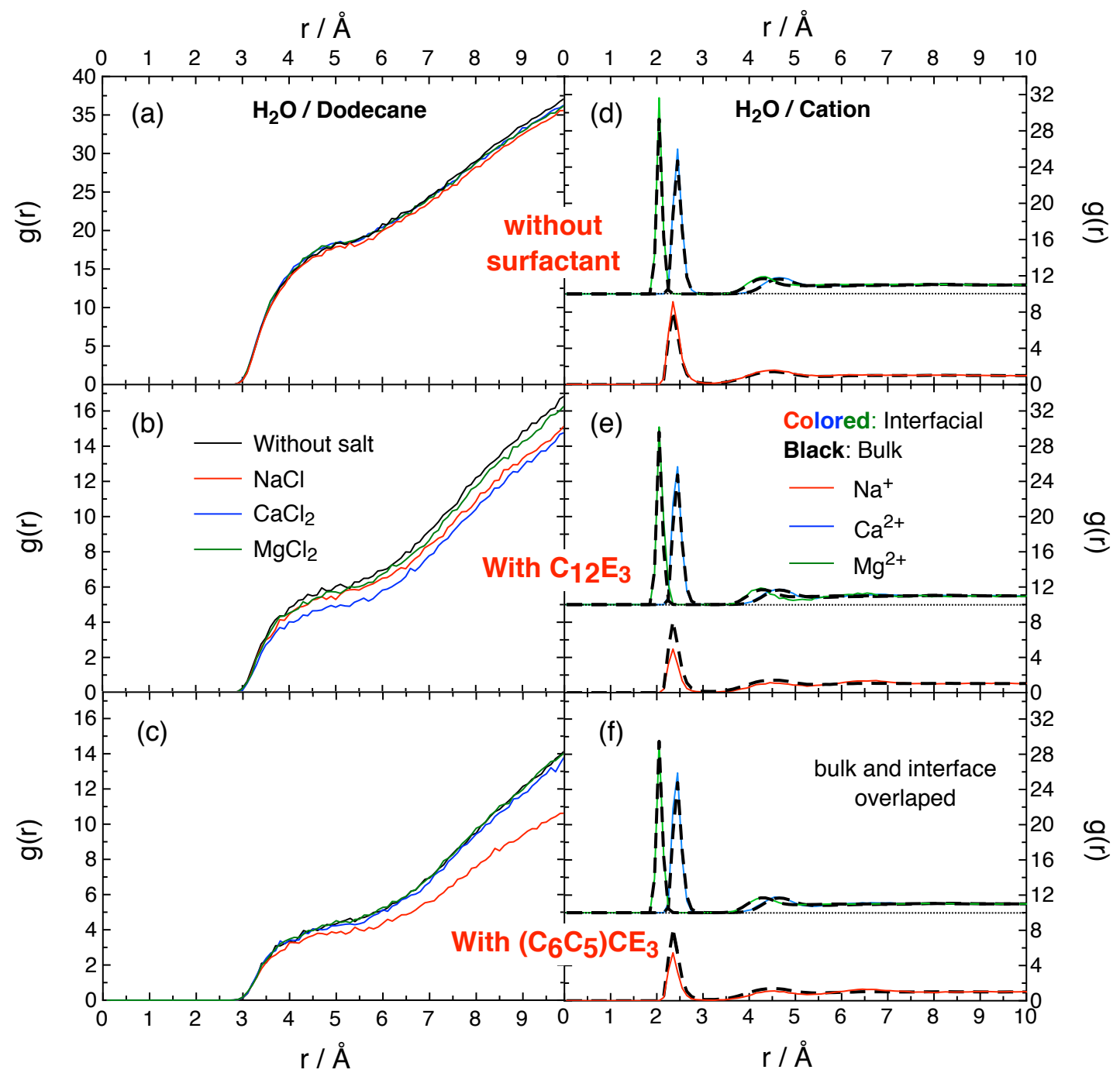

Fig. 5. In (a), (b) and (c) water/dodecane RDFs and in (d), (e) and (f) water/cation RDFs for molecules close to the interface in systems with and without surfactants. The black dashed lines in (d), (e) and (f) refer to the RDF of species at bulk. To build the pair-wise distributions for molecular groups, we considered the $\mathrm{O}$ atoms for water and the $12 \mathrm{CH}_{\mathrm{x}}$ groups for dodecane. The results correspond to the simulations performed with CLAYFF force field for salts at $300 \mathrm{~K}$ and $1 \mathrm{~atm}$. 
519 Then, we analyzed how the coordination spheres of interfacial cations were perturbed 520 with respect the cations at the bulk. To that end, water/cation RDFs were built 521 differentiating two regions: (i) the water bulk and (ii) the interface. The interface cations 522 were selected by listing all $\mathrm{Na}^{+}, \mathrm{Ca}^{2+}$ or $\mathrm{Mg}^{2+}$ located at less than $15 \AA$ from any dodecane 523 molecule, which means that are at $15 \AA$ from the oil phase. The rest are considered bulk 524 cations. In absence of surfactant (Fig. 5d), there is no difference between the coordination 525 spheres of interfacial or bulk cations. However, in presence of any surfactant (Fig. 5e and 526 Fig. 5f), the solvation spheres of interfacial $\mathrm{Na}^{+}$are reduced a $40 \%$ with respect bulk $527 \mathrm{Na}^{+}$. This result suggests that $\mathrm{Na}^{+}$is losing part of its solvation sphere to interact closely 528 with the surfactant. Notice that this is a necessary process to induce salt-surfactant 529 synergistic effects because water layers screen the electrostatic charges of ions in 530 solution, weakening the interactions between salt ions and surfactants. On the other hand, 531 this effect is not seen with $\mathrm{Ca}^{2+}$ and $\mathrm{Mg}^{2+}$ because their interactions with water are too 532 strong to be broken. Concretely, $\mathrm{Na}^{+}$has a relatively weak hydration sphere with a 533 hydration enthalpy of $-98 \mathrm{kcal} / \mathrm{mol}$ [72], whereas $\mathrm{Ca}^{2+}$ or $\mathrm{Mg}^{2+}$ have -377 and -459 $534 \mathrm{kcal} / \mathrm{mol}$, respectively [72]. These experimental information of hydration enthalpies 535 support the conclusion that the surfactant is capable of breaking part of the hydration 536 sphere of $\mathrm{Na}^{+}$but is not strong enough to separate the divalent cations from their hydration 537 sphere, as seen by water/cation RDFs.

538 Fig. 6 shows the more relevant changes due to salinity in RDFs of a system with each 539 surfactant. First, (Fig. 6a and Fig. 6b) show the distributions between water and the 540 surfactant head groups, where large peaks appear at $2.75 \AA$, denoting the average 541 interacting distance between water and the head groups. $\mathrm{MgCl}_{2}$ does not affect water542 surfactant interactions (i.e., the distribution is identical to the RDF without salt), which 543 implies that it interacts very weakly with the head groups, followed by $\mathrm{CaCl}_{2}$ (i.e., the 544 peak in the distribution is slightly lower than with $\mathrm{MgCl}_{2}$ ). However, this peak disappears 545 completely in presence of $\mathrm{NaCl}$, which suggest that $\mathrm{Na}^{+}$is sequestering the surfactant 546 head groups to prevent water/surfactant interactions. Notice that the systems with IFT 547 reduction effects are also the ones where the cation and the surfactant lose their solvation 548 sphere to interact with each other. 
With $\mathrm{C}_{12} \mathrm{E}_{3}$

With $\left(\mathrm{C}_{6} \mathrm{C}_{5}\right) \mathrm{CE}_{3}$

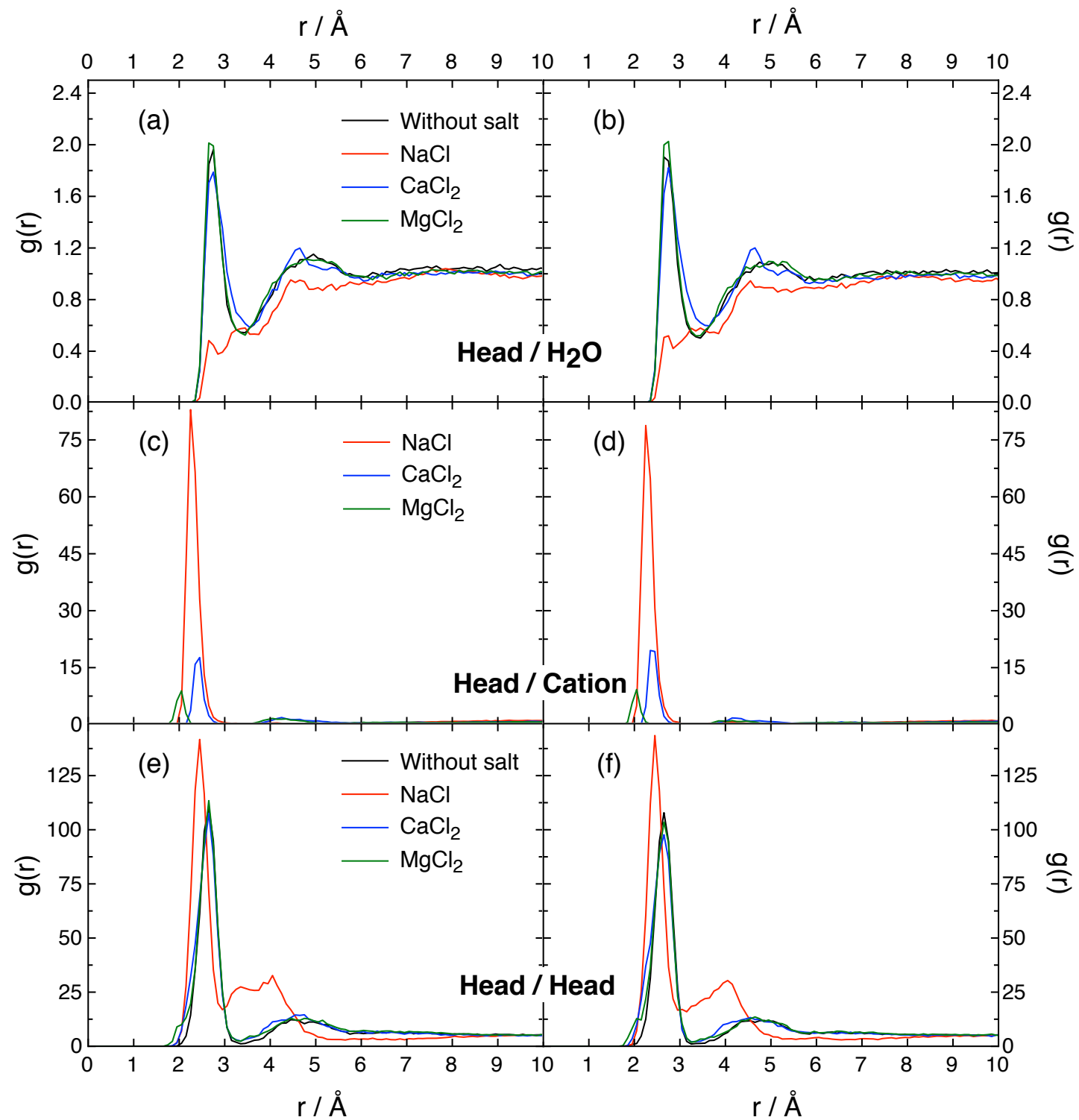

Fig. 6. RDF between surfactant head groups and water $(a, b)$, head groups and the cations (c,d) or head groups with other head groups (e,f). To build the pair-wise distribution for molecular groups, we considered the $\mathrm{O}$ atoms for water and the $\mathrm{O}$ of the head groups for the surfactant heads. The results correspond to the simulations performed with CLAYFF force field for salts at $300 \mathrm{~K}$ and $1 \mathrm{~atm}$.

550 Then, if we evaluate the distributions between the head groups and the ions (Fig. 6c and 551 Fig. 6d) we confirm the previous affirmation. $\mathrm{Na}^{+}$forms a very high and narrow peak at $5522.25 \AA$, which denotes the strong salt-surfactant interaction. $\mathrm{CaCl}_{2}$ and $\mathrm{MgCl}_{2}$ form peaks 553 in similar position but significantly lower in height, following the same trend than in Fig. 554 6a-b (i.e., $\mathrm{Ca}^{2+}$ has a stronger interaction with the surfactant head groups than $\mathrm{Mg}^{2+}$ ).

555 From these results, we can conclude that the surfactant head group is the responsible 556 moiety that interacts with $\mathrm{Na}^{+}$and force it to release from its hydration sphere. 
557 Finally, salinity also affects how surfactants are arranged among themselves. In Fig. 6e 558 and Fig. $6 f$ one can see the head-head group distributions that, in absence of salt, form a 559 high peak at $2.65 \AA$ and a wider lower peak around $4.75 \AA$. However, in the presence of $560 \mathrm{NaCl}$ the first peak is displaced to $2.45 \AA$ and the $2^{\text {nd }}$ peak to less than $4 \AA$, increasing 561 both peaks in height. This result suggests that $\mathrm{NaCl}$ not only sequestrates the head groups 562 from water, but also brings surfactants closer to each other (i.e., an enhanced interfacial 563 packing).

564 Notice that the enhanced packing here validated, was already proposed by 565 experimentalists to explain IFT reduction through a larger accumulation of surfactants at 566 the interface $[20,21]$. However, in our MD simulations all surfactant molecules are 567 already at the interface and the IFT is still reduced, which suggests that the salt-surfactant 568 synergistic effect also includes all phenomena described throughout this work. 569 Additionally, the change of environment around the surfactant head groups (i.e., less 570 surfactant/water interactions) does not imply that the surfactant is losing its interfacial 571 activity, but it just interacts strongly with the cations that form the electric double layer 572 at the interface.

573 The results obtained in this final section suggest that $\mathrm{Na}^{+}$is releasing from its hydration 574 shell to strongly interact with the surfactant head groups, effectively sequestrating them 575 from water. The new arrangement between surfactants and salt forces the head groups to 576 be more planar with respect to the interfacial plane, occupying more area and slightly 577 expelling dodecane molecules from the interface, which increases the efficiency of the 578 surfactant. Similar effects are seen with $\mathrm{Ca}^{2+}$ but in a much weaker extent, whereas $\mathrm{Mg}^{2+}$ 579 is almost not modifying any salt-surfactant interfacial property, ranking the effects as $\mathrm{Na}^{+}$ $580>\mathrm{Ca}^{2+}>\mathrm{Mg}^{2+}$. The aforementioned interactions also induce a tighter packing of the 581 surfactant head groups. This packing could potentially allow additional surfactant 582 molecules to accumulate at the interface to further reduce the IFT, which is a mechanism 583 that was already deduced from experimental observations, and is here validated through 584 molecular dynamics simulations. 


\section{Conclusion}

587 With the aim of explaining the experimentally observed salt-surfactant synergistic effect

588 from a microscopic point of view we have performed MD simulations to study how

589 different salts (i.e., $\mathrm{NaCl}, \mathrm{CaCl}_{2}$ and $\mathrm{MgCl}_{2}$ ) affect the interfacial properties of three

590 different systems: (i) a pure water/dodecane system, (ii) the same system with additional

591 linear non-ionic surfactants (i.e., water/dodecane $/ \mathrm{C}_{12} \mathrm{E}_{3}$ ) and (iii) the first system with

592 additional ramified non-ionic surfactants (i.e., water/dodecane/( $\left.\left.\mathrm{C}_{6} \mathrm{C}_{5}\right) \mathrm{CE}_{3}\right)$. In this study

593 we have been able to confirm that salt ions are capable of interacting with the surfactants

594 changing their interfacial molecular distribution and thus affecting the IFT.

595 In summary, we have observed that cations can potentially release from its hydration 596 sphere to interact with the surfactant head groups preventing surfactant-water 597 interactions. These interactions affect the surfactant distributions at the interface, 598 reducing the distance between surfactant head groups. This mechanism was proposed 599 experimentally and is validated by the currently MD simulations but is not sufficient to 600 explain the salt-surfactant synergistic effect on its own. Other processes are involved in 601 lowering the IFT below the CMC, such as the more planar distribution of surfactants in presence of salt. Altogether, below the $\mathrm{CMC}$, salinity helps the surfactants to rearrange and occupy more interfacial area, reducing the water/dodecane interactions and ultimately decreasing the IFT. The strong attraction felt by cations towards the surfactant molecules can lead to an increase of the interfacial excess of the salt, even achieving positive values for the $\Gamma_{\text {salt }}^{w}$ (i.e., instead of the common negative values). From these results one can conclude that salt ions could (in certain conditions) accumulate at the interface and contribute to the IFT reduction as any other surface-active compound. On the other hand, anions feel less attraction from the surfactants than cations, which generates an electric double layer that polarizes the interface, being a possible additional cause of IFT reduction. The effects observed are not equivalent with all cations. Specifically, $\mathrm{Na}^{+}$ seems to be the strongest interaction moiety because it can release from its hydration

613 sphere more easily, whereas $\mathrm{Ca}^{2+}$ and $\mathrm{Mg}^{2+}$ present significantly weaker salt-surfactant 614 interactions because their coulombic interactions become screened by their strongly 615 bonded solvation water molecules. This ranks the salt-surfactant synergistic effect in this 616 particular system to be $\mathrm{Na}^{+}>\mathrm{Ca}^{2+}>\mathrm{Mg}^{2+}$. Finally, the ramified surfactant is more 617 effective than the linear surfactant in occupying the interface, which makes the salt618 surfactant synergistic effect more noticeable. 
619 All of the previously described effects are capable of slightly reducing the IFT of the

620 system by a relatively small amount and are not capable of achieving ultralow IFT on

621 their own. For this reason, even though the salt-surfactant effect here described works in

622 favor of oil recovery, it could be easily overcome by other interactions that hamper oil

623 extraction in high salinity environments.

624

\section{Declaration of Competing Interest}

626 The authors have no competing of interests to declare.

627

\section{Acknowledgments}

629 This work was supported by the Spanish Ministerio de Economía y Competitividad grant 630 (RTI2018-094757-B-I00), the Spanish Structures of Excellence María de Maeztu 631 program through grant MDM-2017-0767 and the Generalitat de Catalunya grants 632 (2014SGR1582, 2017SGR13, and XRQTC). G.A. thanks the University of Barcelona for 633 both the APIF predoctoral grant and the APIF stay grant at Universidad de Concepción 634 (Chile).

635

636 Appendix A. Supplementary material

637 Supplementary material to this article can be found online at:

638

\section{References}

640 [1] J.J. Sheng, Status of surfactant EOR technology, Petroleum. 1 (2015) 97-105.

641 [2] M.S. Kamal, I.A. Hussein, A.S. Sultan, Review on Surfactant Flooding: Phase 642 Behavior, Retention, IFT, and Field Applications, Energ. Fuel. 31 (2017) 7701-7720.

643 [3] B. Song, X. Hu, X. Shui, Z. Cui, Z. Wang, A new type of renewable surfactants 644 for enhanced oil recovery: Dialkylpolyoxyethylene ether methyl carboxyl betaines, 645 Colloid. Surface. A. 489 (2016) 433-440.

646 [4] N. Morrow, J. Buckley, Improved Oil Recovery by Low-Salinity Waterflooding, 647 J. Pet. Technol. 63 (2011) 106-112.

648 [5] P.P. Jadhunandan, Effects of Brine Composition, Crude Oil, and Aging 649 Conditions on Wettability and Oil Recovery, PhD Dissertation, New Mexico Institute of 650 Mining \& Technology, 1990.

651 [6] W. von Rybinski, B. Guckenbiehl, H. Tesmann, Influence of Co-Surfactants on 652 Microemulsions with Alkyl Polyglycosides, Colloid. Surface. A. 142 (1998) 333-342. 
653 [7] Lu, J., Development of Novel Surfactants and Methods for Chemical Enhanced 654 Oil Recovery, PhD Dissertation, University of Texas, 2014.

655 [8] Z. Jeirani, B. Mohamed Jan, B. Si Ali, I.M. Noor, C.H. See, W. Saphanuchart, 656 Formulation, Optimization and Application of Triglyceride Microemulsion in Enhanced 657 Oil Recovery, Ind. Crops Prod. 43 (2013) 6-14.

658 [9] A.E. Silva, G. Barratt, M. Chéron, E.S.T. Egito, Development of Oil-in-Water 659 Microemulsions for the Oral Delivery of Amphotericin B, Int. J. Pharm. 454 (2013) 641660648.

661 [10] A.M. Howe, A. Clarke, J. Mitchell, J. Staniland, L. Hawkes, C. Whalan, 662 Visualising Surfactant Enhanced Oil Recovery, Colloid. Surface. A. 480 (2015) 449-461. 663 [11] T. Al-Sahhaf, A. Elkamel, A.S. Ahmed, A.R. Khan, The Influence of 664 Temperature, Pressure, Salinity, and Surfactant Concentration on the Interfacial Tension 665 of the N-Octane-Water System, Chem. Eng. Commun. 192 (2005) 667-684.

666 [12] A. Bera, A. Mandal, B.B. Guha, Synergistic Effect of Surfactant and Salt Mixture 667 on Interfacial Tension Reduction between Crude Oil and Water in Enhanced Oil 668 Recovery, J. Chem. Eng. Data. 59 (2014) 89-96.

669 [13] X. Chen, S.S. Adkins, Q.P. Nguyen, A.W. Sanders, K.P. Johnston, Interfacial 670 Tension and the Behavior of Microemulsions and Macroemulsions of Water and Carbon 671 Dioxide with a Branched Hydrocarbon Nonionic Surfactant, J. Supercrit. Fluids. 55 672 (2010) 712-723.

673 [14] V.B. Fainerman, S.V. Lylyk, E.V. Aksenenko, N.M. Kovalchuk, V.I. Kovalchuk, 674 J.T. Petkov, R. Miller, Effect of Water Hardness on Surface Tension and Dilational 675 Visco-Elasticity of Sodium Dodecyl Sulphate Solutions, J. Colloid Interface Sci. 377 676 (2012) $1-6$.

677 [15] A. Ge, Q. Peng, H. Wu, H. Liu, Y. Tong, T. Nishida, N. Yoshida, K. Suzuki, T. 678 Sakai, M. Osawa, S. Ye, Effect of Functional Group on the Monolayer Structures of 679 Biodegradable Quaternary Ammonium Surfactants, Langmuir. 29 (2013) 14411-14420. 680 [16] T. Jiao, X. Liu, J. Niu, Effects of Sodium Chloride on Adsorption at Different 681 Interfaces and Aggregation Behaviors of Disulfonate Gemini Surfactants, RSC Adv. 6 682 (2016) 13881-13889.

683 [17] A.M. Johannessen, K. Spildo, Enhanced Oil Recovery (EOR) by Combining 684 Surfactant with Low Salinity Injection, Energ. Fuel. 27 (2013) 5738-5749. 
685 [18] P. Koelsch, H. Motschmann, Varying the Counterions at a Charged Interface, 686 Langmuir. 21 (2005) 3436-3442.

687 [19] S. Kumar, A. Mandal, Studies on Interfacial Behavior and Wettability Change 688 Phenomena by Ionic and Nonionic Surfactants in Presence of Alkalis and Salt for 689 Enhanced Oil Recovery, Appl. Surf. Sci. 372 (2016) 42-51.

690 [20] Z. Liu, Z. Li, X. Song, J. Zhang, L. Zhang, L. Zhang, S. Zhao, Dynamic Interfacial 691 Tensions of Binary Nonionic-Anionic and Nonionic Surfactant Mixtures at Water692 Alkane Interfaces, Fuel. 135 (2014) 91-98.

693 [21] Z. Liu, L. Zhang, X. Cao, X. Song, Z. Jin, L. Zhang, S. Zhao, Effect of Electrolytes 694 on Interfacial Tensions of Alkyl Ether Carboxylate Solutions, Energ. Fuel. 27 (2013) $695 \quad 3122-3129$.

696 [22] K. Staszak, D. Wieczorek, K. Michocka, Effect of Sodium Chloride on the 697 Surface and Wetting Properties of Aqueous Solutions of Cocamidopropyl Betaine, J. 698 Surfactants Deterg. 18 (2015) 321-328.

699 [23] A. Witthayapanyanon, E.J. Acosta, J.H. Harwell, D.A. Sabatini, Formulation of 700 Ultralow Interfacial Tension Systems Using Extended Surfactants, J. Surfactants Deterg. 7019 (2006) 331-339.

702 [24] H. Francke, M. Thorade, Density and Viscosity of Brine: An Overview from a 703 Process Engineers Perspective, Chem. Erde - Geochem. 70 (2010) 23-32.

704 [25] O. Ozdemir, S.I. Karakashev, A.V. Nguyen, J.D. Miller, Adsorption and Surface 705 Tension Analysis of Concentrated Alkali Halide Brine Solutions, Miner. Eng. 22 (2009) $706 \quad 263-271$.

707 [26] A.A. Zavitsas, Properties of Water Solutions of Electrolytes and Nonelectrolytes, 708 J. Phys. Chem. B. 105 (2001) 7805-7817.

709 [27] H. Aghdastinat, S. Javadian, A. Tehrani-Bagha, H. Gharibi, Spontaneous 710 Formation of Nanocubic Particles and Spherical Vesicles in Catanionic Mixtures of Ester-

711 Containing Gemini Surfactants and Sodium Dodecyl Sulfate in the Presence of 712 Electrolyte, J. Phys. Chem. B. 118 (2014) 3063-3073.

713 [28] P. Mukerjee, C.C. Chan, Effects of High Salt Concentrations on the Micellization 714 of Octyl Glucoside: Salting-Out of Monomers and Electrolyte Effects on the 715 Micelle-Water Interfacial Tension, Langmuir. 18 (2002) 5375-5381.

716 [29] V. Seredyuk, E. Alami, M. Nydén, K. Holmberg, A.V. Peresypkin, F.M. Menger, 
717 Adsorption of Zwitterionic Gemini Surfactants at the Air-Water and Solid-Water 718 Interfaces, Colloid. Surface. A. 203 (2002) 245-258.

719 [30] Z. Zhao, C. Bi, Z. Li, W. Qiao, L. Cheng, Interfacial Tension Between Crude Oil 720 and Decylmethylnaphthalene Sulfonate Surfactant Alkali-Free Flooding Systems, 721 Colloid. Surface. A. 276 (2006) 186-191.

722 [31] H. Schott, Saturation Adsorption at Interfaces of Surfactant Solutions, J. Pharm. 723 Sci. 69 (1980) 852-854.

724 [32] J. W. Gibbs, The Colected Works of J. W. Gibbs, Longmans Green, New York, 7251931.

726 [33] C. Yang, W. Lin, Q. Wang, B. Niu, X. He, Inorganic Salts Effect on Adsorption 727 Behavior of Surfactant AEC at Liquid/Liquid Interface, Res. J. Appl. Sci. Eng. Technol. $728 \quad 6(2013)$ 1424-1427.

729 [34] T. Zhao, G. Xu, S. Yuan, Y. Chen, H. Yan, Molecular Dynamics Study of Alkyl 730 Benzene Sulfonate at Air/Water Interface: Effect of Inorganic Salts, J. Phys. Chem. B. $731 \quad 114(2010) 5025-5033$.

732 [35] S. Yuan, Y. Chen, G. Xu, Molecular Dynamics Studies on Octadecylammonium 733 Chloride at the Air/Liquid Interface, Colloid. Surface. A. 280 (2006) 108-115.

734 [36] Q. Xie, Y. Chen, L. You, M.M. Hossain, A. Saeedi, Drivers of Wettability 735 Alteration for Oil/Brine/Kaolinite System: Implications for Hydraulic Fracturing Fluids 736 Uptake in Shale Rocks, Energies. 11 (2018) 1666:1-13.

737 [37] S. Plimpton, Fast Parallel Algorithms for Short-Range Molecular Dynamics, J. 738 Comput. Phys. 117 (1995) 1-19.

739 [38] W. Wagner, A. Pruß, The IAPWS Formulation 1995 for the Thermodynamic 740 Properties of Ordinary Water Substance for General and Scientific Use, J. Phys. Chem. 741 Ref. Data. 31 (2002) 387-535.

742 [39] E.W. Lemmon, M.L. Huber, Thermodynamic Properties of $n$-Dodecane, Energ. 743 Fuel. 18 (2004) 960-967.

744 [40] T. Schneider, E. Stoll, Molecular-Dynamics Study of a Three-Dimensional One745 Component Model for Distortive Phase Transitions, Phys. Rev. B. 17 (1978) 1302-1322.

746 [41] S. Nosé, A Molecular Dynamics Method for Simulations in the Canonical 747 Ensemble, Mol. Phys. 52 (1984) 255-268.

748 [42] H.J.C. Berendsen, J.P.M. Postma, W.F. van Gunsteren, A. DiNola, J.R. Haak, 
749 Molecular Dynamics With Coupling to an External Bath, J. Chem. Phys. 81 (1998) 36847503690.

751 [43] W.G. Hoover, Constant-Pressure Equations of Motion, Phys. Rev. A. 34 (1986) $752 \quad 2499-2500$.

753 [44] M.G. Martin, J.I. Siepmann, Transferable Potentials for Phase Equilibria. 1. 754 United-Atom Description of n-Alkanes, J. Phys. Chem. B. 102 (1998) 2569-2577.

755 [45] J. Wang, R.M. Wolf, J.W. Caldwell, P.A. Kollman, D.A. Case, Development and 756 Testing of a General Amber Force Field, J. Comput. Chem. 25 (2004) 1157-1174.

757 [46] W.L. Jorgensen, J. Chandrasekhar, J.D. Madura, R.W. Impey, M.L. Klein, 758 Comparison of Simple Potential Functions for Simulating Liquid Water, J. Chem. Phys. 75979 (1983) 926-935.

760 [47] J.-P. Ryckaert, G. Ciccotti, H.J.C. Berendsen, Numerical Integration of the 761 Cartesian Equations of Motion of a System with Constraints: Molecular Dynamics of n762 Alkanes, J. Comput. Phys. 23 (1977) 327-341.

763 [48] H.W. Horn, W.C. Swope, J.W. Pitera, J.D. Madura, T.J. Dick, G.L. Hura, T. Head764 Gordon, Development of an Improved Four-Site Water Model for Biomolecular 765 Simulations: TIP4P-Ew, J. Chem. Phys. 120 (2004) 9665-9678.

766 [49] D.E. Smith, L.X. Dang, Computer Simulations of $\mathrm{NaCl}$ Association in Polarizable 767 Water, J. Chem. Phys. 100 (1998) 3757-3766.

768 [50] J. Áqvist, Ion-Water Interaction Potentials Derived from Free Energy Perturbation 769 Simulations, J. Phys. Chem. 94 (1990) 8021-8024.

770 [51] D. Beglov, B. Roux, Finite Representation of an Infinite Bulk System: Solvent 771 Boundary Potential for Computer Simulations, J. Chem. Phys. 100 (1998) 9050-9063.

772 [52] H.A. Lorentz, Ueber die Anwendung des Satzes vom Virial in der Kinetischen 773 Theorie der Gase, Ann. Phys. 248 (1881) 127-136.

774 [53] M. P. Allen, D. J. Tildesley, Computer Simulation of Liquids, Oxford University 775 Press, New York, 2017.

776 [54] C. Vega, E. de Miguel, Surface Tension of the Most Popular Models of Water by 777 Using the Test-Area Simulation Method, J. Chem. Phys. 126 (2007) 154707:1-10.

778 [55] C.D. Holcomb, P. Clancy, J.A. Zollweg, A critical study of the simulation of the 779 liquid-vapour interface of a Lennard-Jones fluid, Mol. Phys. 78 (1993) 437-459.

780 [56] D. Duque, L.F. Vega, Some issues on the calculation of interfacial properties by 
molecular simulation, J. Chem. Phys. 121 (2004) 8611-8617.

782 [57] A. Ghoufi, P. Malfreyt, D.J. Tildesley, Computer modelling of the surface tension 783 of the gas-liquid and liquid-liquid interface, Chem. Soc. Rev. 45 (2016) 1387-1409.

784 [58] H. Sun, COMPASS: An ab Initio Force-Field Optimized for Condensed-Phase 785 Applications Overview with Details on Alkane and Benzene Compounds, J. Phys. Chem. 786 B. 102 (1998) 7338-7364.

787 [59] P.P. Ewald, Die Berechnung Optischer und Elektrostatischer Gitterpotentiale, 788 Ann. Phys. 369 (1921) 253-287.

789 [60] J.G. Kirkwood, F.P. Buff, The Statistical Mechanical Theory of Surface Tension, 790 J. Chem. Phys. 17 (2004) 338-343.

791 [61] J.H. Irving, J.G. Kirkwood, The Statistical Mechanical Theory of Transport 792 Processes. IV. The Equations of Hydrodynamics, J. Chem. Phys. 18 (1950) 817-829.

793 [62] W. Humphrey, A. Dalke, K. Schulten, VMD: Visual molecular dynamics, J. Mol. 794 Graph. 14 (1996) 33-38.

795 [63] R. Nagarajan, D.T. Wasan, Measurement of Dynamic Interfacial Tension by an 796 Expanding Drop Tensiometer, J. Colloid Interface Sci. 159 (1993) 164-173.

797 [64] S. Zeppieri, J. Rodríguez, A.L. López de Ramos, Interfacial Tension of Alkane + 798 Water Systems ${ }^{\dagger}$, J. Chem. Eng. Data. 46 (2001) 1086-1088.

799 [65] R. Aveyard, S.M. Saleem, Interfacial Tensions at Alkane-Aqueous Electrolyte 800 Interfaces, J. Chem. Soc., Faraday Trans. 1. 72 (1976) 1609-1617.

801 [66] D. Bhatt, J. Newman, C.J. Radke, Molecular Dynamics Simulations of Surface 802 Tensions of Aqueous Electrolytic Solutions, J. Phys. Chem. B. 108 (2004) 9077-9084.

803 [67] E. Mayoral, E. Nahmad-Achar, Study of Interfacial Tension Between an Organic 804 Solvent and Aqueous Electrolyte Solutions Using Electrostatic Dissipative Particle 805 Dynamics Simulations, J. Chem. Phys. 137 (2012) 194701:1-10.

806 [68] P.K. Weissenborn, R.J. Pugh, Surface Tension of Aqueous Solutions of 807 Electrolytes: Relationship with Ion Hydration, Oxygen Solubility, and Bubble 808 Coalescence, J. Colloid Interface Sci. 184 (1996) 550-563.

809 [69] E.R.A. Lima, B.M. de Melo, L.T. Baptista, M.L.L. Paredes, Specific Ion Effects 810 on the Interfacial Tension of Water/Hydrocarbon Systems, Braz. J. Chem. Eng. 30 (2013) $81155-62$.

812 [70] D. Andrienko, Introduction to Liquid Crystals, J. Mol. Liq. 267 (2018) 520-541. 
813 [71] M. Tintaru, R. Moldovan, T. Beica, S. Frunza, Surface Tension of Some Liquid 814 Crystals in the Cyanobiphenyl Series, Liq. Cryst. 28 (2001) 793-797.

815 [72] D.W. Smith, Ionic Hydration Enthalpies, J. Chem. Educ. 54 (1977) 540-542. 